\title{
BMJ Open The relationship between obesity, hemoglobin A1c and the severity of COVID-19 at an urban tertiary care center in New York City: a retrospective cohort study
}

Gurchetan Randhawa (D) , ${ }^{1}$ Kunzah A Syed, ${ }^{1}$ Kavish Singh, ${ }^{1}$ Sanchit V Kundal, ${ }^{1}$ Sharad Oli, ${ }^{1}$ Michael Silver, ${ }^{2}$ Sumrah A Syed, ${ }^{3}$ Thanunthorn Suban Na Ayutthaya, ${ }^{4}$ Shanado Williams, ${ }^{4}$ Zachary L Lodato, ${ }^{5}$ Vladimir Rozvadovskiy, ${ }^{6}$ Stephan Kamholz, ${ }^{1}$ Lawrence Wolf ${ }^{1}$

To cite: Randhawa $\mathrm{G}$, Syed KA, Singh K, et al. The relationship between obesity, hemoglobin $\mathrm{A} 1 \mathrm{C}$ and the severity of COVID-19 at an urban tertiary care center in New York City: a retrospective cohort study. BMJ Open 2021;11:e044526. doi:10.1136/ bmjopen-2020-044526

- Prepublication history for this paper is available online. To view these files, please visit the journal online (http://dx.doi. org/10.1136/bmjopen-2020044526).

Dr. Kamholz is a deceased author.

Received 06 September 2020 Revised 02 November 2020 Accepted 15 January 2021

\section{Check for updates}

(c) Author(s) (or their employer(s)) 2021. Re-use permitted under CC BY-NC. No commercial re-use. See rights and permissions. Published by BMJ.

For numbered affiliations see end of article.

\section{Correspondence to} Dr Gurchetan Randhawa; grandhawa@maimonidesmed. org

\section{ABSTRACT}

Objectives To determine if obesity and diabetes are risk factors for severe outcomes in COVID-19 and to compare patient outcomes in those two conditions.

Design Retrospective cohort study.

Setting Urban tertiary care center in New York City. Participants 302 patients admitted in an inpatient setting, $\geq 18$ years old, with a laboratory-confirmed diagnosis of COVID-19 via nasal PCR swab were randomly selected. Patients were separated into two cohorts based on their body mass index and hemoglobin A1c. 150 patients were placed in the non-obese, non-diabetic cohort and 152 patients were placed in the corresponding cohort (obesity alone, obesity and diabetes, and diabetes alone).

Measurements Primary outcomes were development of acute kidney injury, commencement of renal replacement therapy, aminotransferase elevation, troponin elevation, lactic acidosis, development of septic shock, use of vasopressors, presence of acute respiratory distress syndrome (ARDS) and intubation. The secondary outcomes were length of stay in days and mortality.

Results Patients with obesity and/or diabetes were more likely to develop ARDS (79 patients vs 57 patients, $p<0.0001)$ and to be intubated (71 patients vs 45 patients, $p=0.0031)$. Patients with obesity and/or diabetes were more likely to require vasopressors ( 60 patients vs 41 patients, $p=0.0284$ ) and to develop lactic acidosis (median $3.15 \mathrm{mmol} / \mathrm{L}$, IQR 1.8 to $5.2 \mathrm{mmol} / \mathrm{L}, \mathrm{p}=0.0432$ ). When comparing patients with diabetes with and without obesity against patients with obesity alone, they were more likely to develop ARDS (87.5\%, $p=0.0305)$. Despite these findings, there was no difference in mortality.

Conclusions In patients hospitalised with COVID-19, those with obesity and/or diabetes were more likely to suffer severe complications, but had negligible differences in mortality. This highlights the importance of close monitoring of patients with these conditions and additional areas of research needed to explain the mortality findings.

\section{Strengths and limitations of this study}

- This article offers a detailed analysis of two commonly encountered comorbidities; it also provides novel findings by comparing and contrasting them, while offering new avenues of research to explain the mortality results.

- This study's designation of acute respiratory distress syndrome is limited, because not every patient had a recorded arterial blood gas.

- Patients who received sedation after being intubated often required the use of vasopressors, which confounds the use of this metric as a proxy for the development of septic shock.

- The use of body mass index in elderly patients is limited, as it underestimates the presence of excess body fat, due to changes in fat distribution that take place with the ageing process.

- Our study is limited by the presence of confounders such as age and other comorbidities, due to the large proportion of elderly patients hospitalised for the treatment of COVID-19 at our institution.

\section{INTRODUCTION}

COVID-19 was initially described in Wuhan, China, in December 2019. ${ }^{1}$ The disease spread worldwide and the first documented case in the USA was reported on 31 January 2020, in Washington state. ${ }^{1}$ New York City later became the epicenter of the pandemic and at the time of writing, it had over 226280 confirmed cases with over 23556 deaths. ${ }^{2}$ As a region, New York City currently ranks seventh overall, globally, in terms of total deaths. ${ }^{2}$ According to viral sequencing, the majority of cases in New York City originated from community spread within the USA as well as overseas, from Europe. ${ }^{3}$ 
Initial research studies identified diabetes and obesity as some of the most predominant comorbidities found in COVID-19 patients. ${ }^{4}$ In a study of 5700 COVID-19 patients in the greater New York City metropolitan area, $41.7 \%$ had obesity and $33.8 \%$ had diabetes. ${ }^{5}$ At the time this study was initiated, there was limited, preliminary data suggesting worse outcomes for COVID-19 patients with these comorbidities; however, despite their prevalence, data comparing and contrasting both of these conditions is lacking, and our study aimed to address these gaps in the literature.

The connection between obesity and diabetes with COVID-19 is related to the proinflammatory state caused by metabolic syndrome, as well as the dysregulated host response to the virus itself. ${ }^{4}$ Adipose tissue is metabolically active and produces proinflammatory molecules, such as adipokines, which contribute to the chronic, low-grade inflammation found in patients with obesity. ${ }^{6}$ Studies demonstrated that patients with obesity have higher levels of $\mathrm{C}$ reactive protein (CRP) and increased levels of proinflammatory cytokines, leading to additional recruitment of macrophages and further continuation of this proinflammatory process. ${ }^{7}$ Diabetes, in addition to obesity, is also characterised by a proinflammatory state. ${ }^{8}$ Patients with diabetes also have higher levels of CRP and levels of proinflammatory cytokines, such as interleukin 6 (IL-6), when compared to patients without diabetes. ${ }^{89}$ IL-6, in particular, is one of the central cytokines implicated in COVID-19's 'cytokine storm,' which causes significant morbidity and mortality. ${ }^{10}$

SARS-CoV-2 avoids the host's initial innate immune response from interferon-I and interferon-III. ${ }^{411}$ This causes the host to overproduce inflammatory chemokines in order to recruit cells such as monocytes, macrophages, dendritic cells and neutrophils to control viral replication. ${ }^{41-16}$ This inappropriate immune response causes monocytes and macrophages to enter the lungs and produce proinflammatory cytokines such as IL-1 $\beta, 6$, 8 , tumour necrosis factor- $\alpha$ and additional chemokines to recruit more effector inflammatory cells. ${ }^{41-16}$ This proinflammatory mechanism creates a positive feedback process causing a 'cytokine storm,' resulting in increasing levels of fluid, diminished gas exchange at the alveolar level, and subsequent acute respiratory distress syndrome (ARDS). ${ }^{41-17}$ This process, in tandem with the already proinflammatory state caused by metabolic syndrome, allows SARS CoV-2 to cause severe morbidity and mortality in patients with diabetes and obesity. ${ }^{4}$

\section{METHODS}

This retrospective, single-institution cohort study used 302 patients that were selected at random out of an eligible pool of 643 patients, between 1 March and 1 June 2020. At the time the study was initiated, there were limited data available from similar studies, and the rate of severe hospitalisations in New York City was higher than the rest of the world (as it became the epicenter of the pandemic). Thus, there was not an adequate estimate of effect size for the study to be prior powered. However, the difference in disease severity was large enough that including all 643 patients would result in an overpowered study. Therefore, we estimated that a sample size of 150 patients per cohort would reflect the difference in disease severity with $80 \%$ power and alpha $=0.05$ using a Fisher's exact test. As a result, there were more patients to choose from, and a random sample of available patients was chosen to reach our powered sample size.

Randomization was conducted using SAS V.9.4. Eligible patients included in the study were aged $\geq 18$ years old, had a confirmed COVID-19 diagnosis by a nasal PCR swab, and only included hospitalised patients. They were divided into two cohorts. Those with an hemoglobin A1c (HgbAlc) $\geq 6.5 \%$ and/or a body mass index (BMI) $\geq 30 \mathrm{~kg} / \mathrm{m}^{2}$ comprised one group ( $\mathrm{n}=152$ patients). Those with an HgbAlc $<6.5 \%$ and a BMI $<30 \mathrm{~kg} / \mathrm{m}^{2}$ were placed in the other group ( $n=150$ patients). Diabetes was defined as having an HgbA1c $\geq 6.5 \%$ and obesity was defined as having a BMI $\geq 30 \mathrm{~kg} / \mathrm{m}^{2}$. One of the hypotheses of the study was that poor glycemic control is associated with worse outcomes for COVID-19 patients; therefore, we decided to group patients according to their HgbAlc and not their diabetic medical history. This simplified grouping of patients and allowed for a greater understanding of long-term glycemic control as a marker for the prognosis and degree of complications of COVID-19. In addition, it provided a laboratory value that confirmed the diagnosis of diabetes mellitus, instead of relying on documentation, which may not always be availableconsidering the challenges of healthcare literacy in the patient population served by our institution.

The primary outcomes measured were the sequelae of COVID-19, including the development of acute kidney injury (AKI), commencement of renal replacement therapy, aminotransferase elevation, elevation in levels of troponin, lactic acidosis, presence of septic shock, use of vasopressors, development of ARDS and the presence of intubation. The secondary outcomes were length of stay (LOS) in days and mortality.

AKI was defined by the by the Kidney Disease Improving Global Outcomes definition. ${ }^{18}$ AKI was defined as a rise in serum creatinine by at least $0.3 \mathrm{mg} / \mathrm{dL}$ that occurred within 48 hours, or by an increase of at least $50 \%$ compared with baseline within the past 1 week, or a urine volume that is less than $0.5 \mathrm{~mL} / \mathrm{kg} /$ hour for at least 6 hours. ${ }^{18}$

Baseline creatinine levels were recorded when available. Similar to AKI, levels of troponin were compared with a patient's baseline. A rise of $\geq 0.04 \mathrm{ng} / \mathrm{mL}$ was considered to be an elevation and was defined as an acute cardiac injury.

Sepsis was defined using Sepsis-2 criteria, which is mandated by the New York State Department of Health, for all New York hospitals. ${ }^{19}$ Sepsis was, therefore, defined as having a source of infection and meeting $\geq 2$ systemic inflammatory response syndrome criteria (temperature $>38^{\circ} \mathrm{C}$ or $<36^{\circ} \mathrm{C}$; heart rate $>90$ beats per minute; 
respiratory rate $>20$ breaths $/ \mathrm{min}$ or alveolar carbon dioxide tension $<32 \mathrm{~mm} \mathrm{Hg}$; white cell count $>12 \times 10^{9} / \mathrm{L}$, $<4 \times 10^{9} / \mathrm{L}$ or $>10 \%$ neutrophil band count)..$^{20}$

Septic shock was defined by the Surviving Sepsis Guidelines. ${ }^{21} 22$ This is sepsis with a lactate level $>2 \mathrm{mmol} / \mathrm{L}$, systolic blood pressure (SBP) less than $90 \mathrm{~mm} \mathrm{Hg}$ or a SBP drop $\geq 40 \mathrm{~mm} \mathrm{Hg}$ from baseline, which persists after adequate fluid resuscitation.

Elevated aminotransferase levels were defined as a rise in the levels of aspartate aminotransferase (AST) and alanine aminotransferase (ALT) to five times the upper limit of normal, corresponding to an AST of $200 \mathrm{IU} / \mathrm{L}$, and an ALT of $300 \mathrm{IU} / \mathrm{L}$.

ARDS was diagnosed based on the following: acute onset, non-cardiac generated bilateral lung infiltrates noted with chest radiography, and a PF ratio (arterial oxygen tension/fractional inspired oxygen) less than $300 \mathrm{~mm} \mathrm{Hg}$. Patients without arterial blood gases (ABGs) were excluded because their PF ratios could not be calculated.
All categorical variables were summarised with frequency and percent, and groups were compared with Fisher's exact test. All continuous variables were checked for symmetry. Symmetry was not upheld; therefore, medians and IQRs were used to summarise the data. A Wilcoxon test was then used to determine group differences. Multivariate models that controlled for age, race and gender were performed and these factors did not affect the results of the study.

\section{Patient and public involvement}

Patients or the public were not involved in the design, or conduct, or reporting, or dissemination plans of our research.

\section{RESULTS}

Table 1 describes the results of the study. There were statistically significant findings with lactic acid levels, elevations in troponin, the presence of ARDS, the presence

\begin{tabular}{|c|c|c|c|c|}
\hline Variable & Value & Low BMI/HgbA1c $n=150$ & High BMI/HgbA1c $n=152$ & $P$ value \\
\hline Age (years) & & $73.5(62-85)$ & $67(59-74.5)$ & 0.0011 \\
\hline \multirow[t]{2}{*}{ Gender } & Male & $96(64 \%)$ & $99(65.13 \%)$ & 0.9043 \\
\hline & Female & $54(36 \%)$ & $53(34.87 \%)$ & \\
\hline \multirow[t]{4}{*}{ Race } & Asian & $15(10 \%)$ & $19(12.5 \%)$ & 0.0405 \\
\hline & Black & $16(10.67 \%)$ & $14(9.21 \%)$ & \\
\hline & White & $96(64 \%)$ & 77 (50.66\%) & \\
\hline & Other/unk/Hisp & $23(15.33 \%)$ & $42(27.63 \%)$ & \\
\hline Baseline creatinine (mg/dL) & & $0.9(0.6-1.1)$ & $0.8(0.6-1.1)$ & 0.2916 \\
\hline Baseline troponin $(\mathrm{ng} / \mathrm{mL})$ & & $0.02(0.01-0.045)$ & $0.03(0.01-0.05)$ & 0.2723 \\
\hline Max ALT (IU/L) & & $39(21-105)$ & $43(27-86)$ & 0.7753 \\
\hline Max AST (IU/L) & & $74(39-141)$ & $68(38-120)$ & 0.1991 \\
\hline Max creatinine (mg/dL) & & $1.9(1-4.3)$ & $1.6(1-3.15)$ & 0.7899 \\
\hline Max lactic acid (mmol/L) & & $2.4(1.8-3.8)$ & $3.15(1.8-5.2)$ & 0.0432 \\
\hline Max troponin (ng/mL) & & $0.08(0.03-0.3)$ & $0.04(0.01-0.13)$ & 0.0062 \\
\hline AKI & Yes & $96(64 \%)$ & $99(65.13 \%)$ & 0.904 \\
\hline ARDS & Yes & $57 / 103$ (55.34\%) & 79/96 (82.29\%) & $<0.0001$ \\
\hline Intubation & Yes & $45(30 \%)$ & $71(46.71 \%)$ & 0.0031 \\
\hline Septic shock & Yes & $44(29.33 \%)$ & $60(39.47 \%)$ & 0.07 \\
\hline Vasopressors & Yes & $41(27.33 \%)$ & $60(39.47 \%)$ & 0.0284 \\
\hline Hemodialysis & Yes & $27(18 \%)$ & $22(14.47 \%)$ & 0.4379 \\
\hline Aminotransferase Elevation & Yes & $25(16.67 \%)$ & $6(3.97 \%)$ & 0.0003 \\
\hline Acute cardiac Injury & Yes & $88(64.71 \%)$ & $72(48 \%)$ & 0.006 \\
\hline LOS (days) & & $9(5-14)$ & $9.5(6-18)$ & 0.1936 \\
\hline Expired & Yes & 67 (44.67\%) & 70 (46.05\%) & 0.8182 \\
\hline
\end{tabular}

Table 1: all categorical variables are summarised with $\mathrm{n}(\%)$ and compared using the Fisher's exact test. All continuous variables were checked for symmetry and summarised with median and IQR range (25th-75th) then compared using the Wilcoxon rank sum test. AKI, acute kidney injury; ALT, alanine aminotransferase; ARDS, acute respiratory distress syndrome; AST, aspartate aminotransferase; BMI, body mass index; HgbA1c, hemoglobin A1c; LOS, length of stay. 


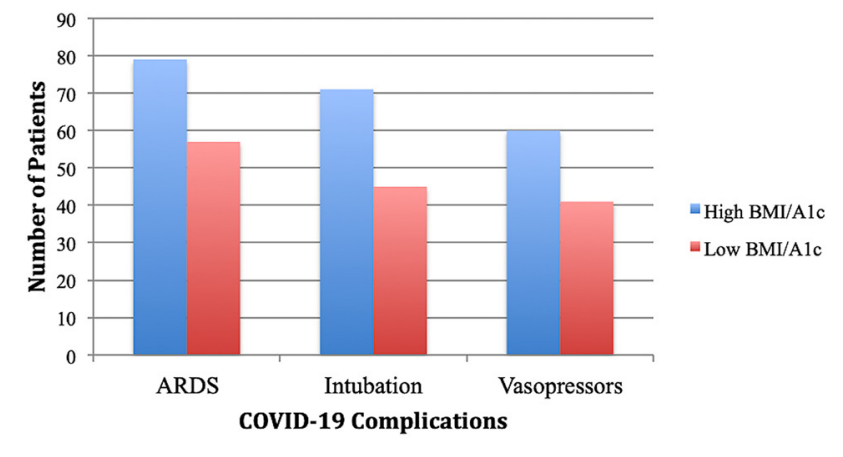

Figure 1 Describes statistically significant differences for the high $\mathrm{BMI} / \mathrm{HgbA} 1 \mathrm{c}$ group versus the low $\mathrm{BMI} / \mathrm{HgbA} 1 \mathrm{c}$ group in terms of the number of patients per COVID-19 complication. ARDS, acute respiratory distress syndrome; BMI, body mass index; HgbA1c, hemoglobin A1c.

of intubation, the use of vasopressors and elevations in aminotransferase levels.

Figure 1 describes statistically significant differences for the high $\mathrm{BMI} / \mathrm{HgbA1}$ c group vs the low BMI/HgbA1c group in terms of the number of patients per COVID-19 complication.

Tables 2 and 3 describe subgroup analysis of the higher BMI/HgbAlc cohort in terms of severe respiratory complications of COVID-19 (intubation and ARDS). Statistically significant findings include a higher rate of ARDS in patients with diabetes with and without obesity compared with patients with obesity alone.

\section{DISCUSSION}

COVID-19 was associated with significant morbidity and mortality in hospitalised patients, according to the results of our study (table 1). Approximately $65 \%$ of patients in both cohorts developed AKI and 16\% required renal replacement therapy. Approximately $34 \%$ of all the patients developed septic shock. Both cohorts had an LOS that averaged approximately 9-10 days. Mortality was also significant, as 67 patients in the low BMI/HgbA1c cohort expired $(44.67 \%)$ and 70 patients in the high BMI/HgbA1c cohort expired (46.05\%). Of note, males constituted $65 \%$ of the patients enrolled in the study.

Statistically significant differences for the low BMI/ HgbA1c group included higher elevated levels of troponin (median $0.08 \mathrm{ng} / \mathrm{mL}$, IQR 0.03 to $0.3 \mathrm{ng} / \mathrm{mL}$, $\mathrm{p}=0.0062)$ and subsequent acute cardiac injury $(64.71 \%$ vs. $48 \%, \mathrm{p}=0.006)$. The low BMI/HgbAlc cohort also had a statistically significant, more frequent development of aminotransferase elevation $(16.67 \%$ vs. $3.97 \%$, $\mathrm{p}=0.0003)$. However, these results are limited, given the small number of total cases (31 patients) combined for both cohorts. In addition, the development of fulminant hepatic failure was rare; therefore, this finding was not clinically significant.

While the cohorts did not have statistically significant differences in terms of the development of septic shock, the higher BMI/HgbA1c group did have statistically significant differences in the development of lactic acidosis (median $3.15 \mathrm{mmol} / \mathrm{L}$, IQR 1.8 to $5.2 \mathrm{mmol} / \mathrm{L}$, $\mathrm{p}=0.0432)$ and the use of vasopressors $(39.47 \%$ vs. $27.33 \%, \mathrm{p}=0.0284$ ). These findings correspond to the higher rates of hypoxia and respiratory distress encountered by this cohort, as hypoxia triggers the production of lactic acidosis, and vasopressors are often required after patients receive sedation while being intubated. As a result, there were statistically significant differences in the development of ARDS (79 patients vs. 57 patients, $\mathrm{p}<0.0001$ ) and of intubation (71 patients vs 45 patients, $\mathrm{p}=0.0031$ ) for the higher BMI/HgbA1c cohort (figure 1). These findings mirrored those of other studies, with the caveat that our study differed in that it demonstrated no statistically significant difference in mortality. ${ }^{23-25}$ We hypothesise that the lower BMI/HgbA1c cohort's statistically significant differences in age (median 73.5 years old, IQR 62 to 85 years old, $\mathrm{p}=0.0011$ ) and acute cardiac injury ( $64.71 \%$ vs $48 \%, \mathrm{p}=0.006$ ) were the reasons for this finding. Several recent studies demonstrated that older patients with COVID-19, when compared to younger patients with COVID-19, had increased mortality, an increased incidence of acute cardiac injury, and acute cardiac injury itself was a predictor for an increased risk of mortality. ${ }^{26}{ }^{27}$ However, additional research is needed to further explain this lack of discrepancy for mortality.

When examining the data from the subgroup analysis (table 2), there were no statistically significant differences in terms of the rates of ARDS and intubation. However, when comparing diabetic patients with and without obesity compared to patients with obesity alone (table 3), there was a statistically significant difference in the development of ARDS (63 patients vs. 16 patients, $\mathrm{p}=0.0305$ ). This suggests that diabetes, not just obesity, plays an important role in the development of respiratory distress leading to ARDS. A retrospective study from China indicated that patients with diabetes as their only comorbidity were more likely to develop a more severe form of pneumonia leading to respiratory distress when

Table 2 Subgroup analysis table \#1

\begin{tabular}{|c|c|c|c|c|c|}
\hline Variable & Value & Obese+diabetes $n=52$ & Obese only $n=40$ & Diabetes only $n=60$ & P value \\
\hline Intubated & Yes & $24(46.2 \%)$ & $15(37.5 \%)$ & $32(53.3 \%)$ & 0.2972 \\
\hline ARDS & Yes & 29/34 (85.3\%) & $16 / 24(66.7 \%)$ & $34 / 38$ (89.5\%) & 0.0615 \\
\hline
\end{tabular}

ARDS, acute respiratory distress syndrome. 
Table 3 Subgroup analysis table \#2

\begin{tabular}{|c|c|c|c|c|}
\hline Variable & Value & Diabetes \pm obesity $n=112$ & Obese only $n=40$ & $P$ value \\
\hline Intubated & Yes & $56(50.0 \%)$ & $15(37.5 \%)$ & 0.1738 \\
\hline ARDS & Yes & 63/72 (87.5\%) & 16/24 (66.7\%) & 0.0305 \\
\hline
\end{tabular}

ARDS, acute respiratory distress syndrome.

compared to patients without diabetes. ${ }^{28}$ Another study compared patients with an HgbA1c $\geq 6.5 \%$ vs patients with an HgbAlc $<6.5 \% .{ }^{29}$ The study demonstrated that patients with insufficient glycemic control (HgbAlc $\geq 6.5 \%$ ) were more likely to be critically ill, develop ARDS, and suffer from secondary respiratory infections, when compared to patients with adequate glycemic control. ${ }^{29}$ In addition, HgbAlc itself was independently associated with mortality. ${ }^{29}$ With regard to hospitalised patients, additional research demonstrated that patients with strict control of blood glucose levels (glycemic variability between 3.9 and $10.0 \mathrm{mmol} / \mathrm{L}$ ) had reduced mortality compared to patients with poor blood glucose control (glycemic variability greater than $10.0 \mathrm{mmol} / \mathrm{L}$ ). ${ }^{30}$ These studies demonstrate the importance of having a baseline HgbA1c level and the importance of tight glycemic control for hospitalised COVID-19 patients.

The large number of elderly patients in this study impacted our interpretation of BMI, for several reasons. ${ }^{31}$ First, BMI does not account for visceral adipose tissue (VAT), which increases on ageing, and therefore, limits BMI's interpretation of excess body fat. ${ }^{31}$ Second, an excess amount of VAT is associated with creating a proinflammatory state, causing the release of proinflammatory cytokines, especially IL-6, which demonstrates its clinical relevance with COVID-19. ${ }^{31}{ }^{33}$ Lastly, a recent study demonstrated that excess VAT is associated with worse clinical outcomes in COVID-19 patients. ${ }^{31}$ This underscores its importance as a potential limiting factor for the use of BMI, as well as its value as a potential clinical marker. ${ }^{31}$ Another study demonstrated that VAT was superior to BMI for predicting the presence of diabetes. ${ }^{34}$ The increased amount of VAT in patients with diabetes is a potential factor explaining some of the different clinical outcomes in our study; however, further research is needed to determine the pathophysiologic link between VAT and COVID-19. ${ }^{31}$

Our study was also limited by other factors as well. It analysed a relatively small cohort of patients, thereby limiting statistical significance of the subgroup analyses. ABG results were limited, as only 103 patients in the nondiabetic/non-obese cohort and 96 patients in the obese and/or diabetic cohort had recorded ABGs. Patients who received sedation after being intubated often required the use of vasopressors, which also limits the use of this metric as a proxy for the development of septic shock. Our study is limited by the presence of confounders such as age, due to the large number of elderly patients treated for COVID-19, as well as the presence of other comorbidities excluding diabetes and obesity.

While our study performed a subgroup analysis using some of the most important, severe complications of COVID-19 (ARDS and intubation), further study is warranted comparing other complications as well. Given the prevalence of diabetes and obesity, the low cost of obtaining HgbA1c levels and BMI recordings on patients, our study can be easily replicated. Challenges to external validity and overall generalisability include the aforementioned limitations detailed above.

\section{CONCLUSION}

This study suggests that patients with diabetes and obesity are more likely to suffer severe complications from COVID-19, most importantly ARDS and intubation, when compared to patients without these morbidities. Despite these clinical findings, there was no difference in mortality, and further research is needed to explore this discrepancy. However, given the prevalence of these comorbidities, hospitalised patients with diabetes and obesity should have their respiratory statuses closely monitored, and clinicians should consider these comorbidities as risk factors for life-threatening complications of COVID-19.

\section{Author affiliations}

${ }^{1}$ Department of Medicine, Maimonides Medical Center, Brooklyn, New York, USA ${ }^{2}$ Department of Research, Maimonides Medical Center, Brooklyn, New York, USA

${ }^{3}$ Department of Family Medicine, Our Lady of Lourdes Memorial Hospital,

Binghamton, New York, USA

${ }^{4}$ St. George's University School of Medicine, True Blue, Grenada ${ }^{5}$ NYIT College of Osteopathic Medicine, Old Westbury, New York, USA

${ }^{6}$ Department of Pharmacy, UConn Health, Farmington, Connecticut, USA

Acknowledgements When this study was initiated, the principal investigator was Dr Stephan Kamholz, MD Sadly, he succumbed to COVID-19 soon thereafter. Dr Kamholz had been a chairman of departments of internal medicine for almost 30 years. His vast medical knowledge and clinical acumen were legendary, as were his warmth, kindness and humility. Generations of physicians learned from this giant among teachers of medicine. The authors of this article dedicate it to him and posthumously thank him for his guidance.

Contributors GR, KAS, SK and and LW contributed to the conception of the original research idea. GR, KAS, KS and SVK collected the data for the study. MS performed the statistical analysis for the study. Both SK and LW served as the principal investigators and supervised the project. All authors (GR, KAS, KS, SVK, S0, MS, TSNA, SW, ZL, SAS, VR, SK and LW) contributed to the writing, editing and/or final approval of the manuscript.

Funding The authors have not declared a specific grant for this research from any funding agency in the public, commercial or not-for-profit sectors.

Competing interests None declared. 
Patient and public involvement Patients and/or the public were not involved in the design, or conduct, or reporting, or dissemination plans of this research.

Patient consent for publication Not required.

Provenance and peer review Not commissioned; externally peer reviewed.

Data availability statement No data are available. An ethical approval was not obtained to make data sharing possible outside of the listed research team; no additional data are available.

Open access This is an open access article distributed in accordance with the Creative Commons Attribution Non Commercial (CC BY-NC 4.0) license, which permits others to distribute, remix, adapt, build upon this work non-commercially, and license their derivative works on different terms, provided the original work is properly cited, appropriate credit is given, any changes made indicated, and the use is non-commercial. See: http://creativecommons.org/licenses/by-nc/4.0/.

\section{ORCID iD}

Gurchetan Randhawa http://orcid.org/0000-0002-4645-7319

\section{REFERENCES}

1 Holshue ML, DeBolt C, Lindquist S, et al. First case of 2019 novel coronavirus in the United States. N Engl J Med 2020;382:929-36.

2 Johns Hopkins University. COVID-19 Dashboard by the center for systems science and engineering (CSSE) at Johns Hopkins University, 2020. Available: https://gisanddata.maps.arcgis.com/ apps/opsdashboard/index.html?fbclid=IwAR30460yfm - HOHC3ROy KYzsUPT2JVpmEC18zlvjOHXdq_2s4eHKTzdJNUI\#/bda7594740fd 40299423467b48e9ecf6

3 Gonzalez-Reiche AS, Hernandez MM, Sullivan MJ, et al. Introductions and early spread of SARS-CoV-2 in the New York City area. Science 2020;369:eabc1917-301.

4 Mauvais-Jarvis F. Aging, male sex, obesity, and metabolic inflammation create the perfect storm for COVID-19. Diabetes 2020;69:1857-63.

5 Richardson S, Hirsch JS, Narasimhan M, et al. Presenting characteristics, comorbidities, and outcomes among 5700 patients hospitalized with COVID-19 in the new York City area. JAMA 2020:323:2052-9.

$6 \mathrm{Kim} \mathrm{JA}$, Choi KM. Newly discovered adipokines: pathophysiological link between obesity and cardiometabolic disorders. Front Physiol 2020;11:568800.

7 Richard C, Wadowski M, Goruk S, et al. Individuals with obesity and type 2 diabetes have additional immune dysfunction compared with obese individuals who are metabolically healthy. BMJ Open Diabetes Res Care 2017;5:e000379.

8 Pickup JC. Inflammation and activated innate immunity in the pathogenesis of type 2 diabetes. Diabetes Care 2004;27:813-23.

9 Pickup JC, Mattock MB, Chusney GD, et al. Niddm as a disease of the innate immune system: association of acute-phase reactants and interleukin-6 with metabolic syndrome X. Diabetologia 1997;40:1286-92.

10 Iwasaki M, Saito J, Zhao H, et al. Inflammation triggered by SARSCoV-2 and ACE2 augment drives multiple organ failure of severe COVID-19: molecular mechanisms and implications. Inflammation 2021;44:13-34

11 Blanco-Melo D, Nilsson-Payant BE, Liu W-C, et al. Imbalanced host response to SARS-CoV-2 drives development of COVID-19. Cell 2020;181:1036-45

12 Mehta P, McAuley DF, Brown M, et al. COVID-19: consider cytokine storm syndromes and immunosuppression. Lancet 2020;395:1033-4.
13 Chen G, Wu D, Guo W, et al. Clinical and immunological features of severe and moderate coronavirus disease 2019. J Clin Invest 2020;130:2620-9.

14 Huang C, Wang Y, Li X, et al. Clinical features of patients infected with 2019 novel coronavirus in Wuhan, China. Lancet 2020;395:497-506.

15 Chousterman BG, Swirski FK, Weber GF. Cytokine storm and sepsis disease pathogenesis. Semin Immunopathol 2017;39:517-28.

16 Ye Q, Wang B, Mao J. The pathogenesis and treatment of the 'Cytokine Storm' in COVID-19. J Infect 2020;80:607-13.

17 Osuchowski MF, Aletti F, Cavaillon J-M, et al. SARS-CoV-2/ COVID-19: evolving reality, global response, knowledge gaps, and opportunities. Shock 2020;54:416-37.

18 Kellum JA, Lameire N, Aspelin P, et al. Kidney disease: improving global outcomes (KDIGO) acute kidney injury work group. KDIGO clinical practice guideline for acute kidney injury. Kidney Int Suppl 2012;2:1-138.

19 New York State Department of Health Sepsis Regulations. Sepsis Regulations: Guidance Document 405.4 (a)(4), 2019. Available: https://www.health.ny.gov/regulations/public_health_law/section/ 405/

20 Levy MM, Fink MP, Marshall JC. SCCM/ESICM/ACCP/ATS/SIS international sepsis definitions conference. Intensive Care Med 2001;2001:530-8.

21 Rhodes A, Evans LE, Alhazzani W, et al. Surviving sepsis campaign. Crit Care Med 2017;45:486-552.

22 Singer M, Deutschman CS, Seymour CW, et al. The third International consensus definitions for sepsis and septic shock (Sepsis-3). JAMA 2016;315:801-10.

23 Anderson MR, Geleris J, Anderson DR, et al. Body mass index and risk for intubation or death in SARS-CoV-2 infection: a retrospective cohort study. Ann Intern Med 2020;173:782-90.

24 Földi M, Farkas N, Kiss S, et al. Obesity is a risk factor for developing critical condition in COVID-19 patients: a systematic review and meta-analysis. Obesity Reviews 2020;21.

25 Malik VS, Ravindra K, Attri SV, et al. Higher body mass index is an important risk factor in COVID-19 patients: a systematic review and meta-analysis. Environ Sci Pollut Res Int 2020;27:42115-23.

26 Luo L, Fu M, Li Y, et al. The potential association between common comorbidities and severity and mortality of coronavirus disease 2019: a pooled analysis. Clin Cardiol 2020;43:1478-93.

27 Wei C, Liu Y, Liu Y, et al. Clinical characteristics and manifestations in older patients with COVID-19. BMC Geriatr 2020;20:395.

28 Guo W, Li M, Dong Y, et al. Diabetes is a risk factor for the progression and prognosis of COVID -19. Diabetes Metab Res Rev 2020;36:e3319.

29 Liu L, Wei W, Yang K, et al. Glycemic control before admission is an important determinant of prognosis in patients with coronavirus disease 2019. J Diabetes Investig 2020;208.

30 Zhu L, She Z-G, Cheng X, et al. Association of blood glucose control and outcomes in patients with COVID-19 and pre-existing type 2 diabetes. Cell Metab 2020;31:1068-77.

31 Watanabe M, Caruso D, Tuccinardi D, et al. Visceral fat shows the strongest association with the need of intensive care in patients with COVID-19. Metabolism 2020;111:154319.

32 Batsis JA, Mackenzie TA, Bartels SJ, et al. Diagnostic accuracy of body mass index to identify obesity in older adults: NHANES 19992004. Int J Obes 2016;40:761-7.

33 Hotamisligil GS. Inflammation and metabolic disorders. Nature 2006:444:860-7.

34 Jung SH, Ha KH, Kim DJ. Visceral fat mass has stronger associations with diabetes and prediabetes than other anthropometric obesity indicators among Korean adults. Yonsei Med J 2016;57:674-80. 